\title{
An Update of the Recent Developments on Amblyopia
}

\author{
Abdulmajeed Alharbi ${ }^{*}$, Hosam Dahaim Al Harbi2\# \\ ${ }^{1}$ Department of Ophthalmology, Qassim University, Qassim, KSA \\ ${ }^{2}$ College of Medicine, Qassim University, Qassim, KSA \\ Email: *mavric77@gmail.com
}

How to cite this paper: Alharbi, A. and $\mathrm{Al}$ Harbi, H.D. (2020) An Update of the Recent Developments on Amblyopia. Open Journal of Ophthalmology, 10, 241-254. https://doi.org/10.4236/ojoph.2020.103026

Received: July 20, 2020

Accepted: August 23, 2020

Published: August 26, 2020

Copyright $\odot 2020$ by author(s) and Scientific Research Publishing Inc. This work is licensed under the Creative Commons Attribution-NonCommercial International License (CC BY-NC 4.0). http://creativecommons.org/licenses/by-nc/4.0/ (c) (i) (5) Open Access

\begin{abstract}
Amblyopia is a neurodevelopmental disorder of the visual cortex arising from abnormal visual experience early in life. Amblyopia is a major cause of impaired vision in infants and young children (prevalence around 3.5\%). There are different treatment options for amblyopia based on its severity and age of the patient. Traditional treatments include patching or occlusion of the dominant eye and pharmacological penalisation using Atropine (1\%). Recent developments in amblyopia management have found success with the use of binocular exercises and certain modifications of glasses and contact lenses. The critical age up to which amblyopia is treatable or reversible is also being pushed up with more research. With newer advancements in amblyopia therapy, the success rate is also improving with multimodal approach.
\end{abstract}

\section{Keywords}

Amblyopia, Visual Circuit, Anisometropic Amblyopia, Strabismus, Visual Deprivation, Reverse Amblyopia, Occlusion, Binocular Therapy, Penalisation, Orthoptics

\section{Introduction}

Amblyopia is characterized as an "abatement of visual sharpness for which no causes can be distinguished by the physical assessment of the eye, brought about by vision hardship or unusual binocular interaction" [1]. The American Academy of Ophthalmology looks at amblyopia as an intraocular contrast of 2 lines or more in a visual keenness table (without indicating any), or visual keenness more regrettable than or equivalent to $20 / 30$ with the best optical correction [2]. It is one of the most well-known purposes behind decreased visual keenness in youngsters ${ }^{\#}$ Medical Intern. 
and moderately aged populaces. $2 \%$ - $5 \%$ of everybody is influenced by amblyopia of this age group [3]. A few ophthalmologists accept amblyopia which gets lasting by 6 - 7 years old, while others accept it's still treatable up to 9 - 10 years old [4] [5] [6] [7] [8]. It's dependent on the "basic time" of visual improvement in people. In any case, this idea is dicey now, the same number of review case arrangement is indicating improvement in visual sharpness up to 19 yrs [9] [10] [11].

\section{Pathophysiology}

Amblyopia is essential imperfection of focal sensory system.

Diverse visual capacities are not completely evolved during childbirth; their full improvement relies upon 3 basic conditions during the basic time of visual advancement in outset: satisfactory upgrades got from each eye, visual parallelism (relating pictures), and trustworthiness of the visual pathways [12]-[22].

Unsettling influences on contribution of upgrades got by visual cortex during this plastic and insecure phase of visual advancement keep appropriate utilization of contributions from the included eye, coming full circle in amblyopia. The effect on the visual framework is firmly identified with the time at which the visual aggravation starts, and its power, type, and duration [23].

At the point when the visual boost issue is gifted, extreme, unidentified, and not turned around in the primary months or long stretches of life, it can prompt significant auxiliary adjustment of the visual neuronal circuit, causing complete morphological changes in cortical structures of the sidelong geniculate core (LGN) and visual cortex, which lead to conclusive modifications in the last visual capacity of amblyopic eyes [24].

At the point when the visual boost issue comes later and with less power, the typical life structures development of the framework is kept up, however it is as yet conceivable to have dynamic restraint from neurons of the ordinary eye on neurons of the influenced eye, likewise prompting utilitarian amblyopia. This neurological system represses the picture of the influenced eye trying to not upset the preparing of the ordinay eye [25].

This basic period stretches out from birth to $7-8$ years old. After this age, cortical versatility decreases yet it's never lost till the age of 50 years. Subsequently, it's accepted now that, if there are any methods of re-establishing pliancy of the cortical hardware, amblyopia is curable [25].

\section{Risk Factors}

Risk factors for amblyopia are untimely birth, little for gestational age, formative deferral, or having a first-degree relative with amblyopia. Natural variables, including maternal substance maltreatment during pregnancy have been accounted for to be related with an expanded danger of amblyopia. Be that as it may, a few investigations have invalidated the same [26]-[40].

Strabismus, refractive mistake, waterfall, and ptosis, happening during this basic period are exceptionally amblyopiogenic [41]. 


\section{Types of Amblyopia}

1) Deprivation amblyopia develops when different types of eye diseases prevent light from reaching retina, during critical period, it prevents the proper formation of visual circuit. It could be due to media opacity, optic nerve defect or movement disorder (nystagmus). Few examples are congenital cataract, blepharoptosis, nystagmus disorders, optic nerve coloboma and hypoplasia, retinal disorders, persistent fatal vasculature, corneal opacities involving visual axis.

It is the most difficult and challanging form of amblyopia because profound anatomical changes in visual curcuit are seen here. The management of such condition too need a lot of attention and less successful compared to other forms of amblyopia. It effects all other visual functions as well [42] [43] [44] [45].

The ideal period to treat the causes of deprivation in humans is within the first six months of life; after that, the chance to ensure the effectiveness of treatment and achieve normal results decreases rapidly the severity of deprivation makes a difference in these first 6 months. For instance, dense bilateral cataracts not treated by 3 months of age will almost assuredly lead to the development of nystagmus, which will severely limit visual acuity permanently. Anisometropic amblyopia, uncorrected refractive mistake are viewed as the most widely recognized reason for amblyopia. There are two principle kinds of refractive amblyopia, anisometropic and isoametropic amblyopia. Anisometropic amblyopia alludes to contrast in the condition of refraction of at any rate 1 diopter between 2 eyes [46]. Isoametropic amblyopia happens when the two eyes are amblyopic from a noteworthy yet comparable refractive mistake. Seriousness of the refractive blunder and the amblyopia are straightforwardly related. Anisometropic amblyopia is likely within the sight of $1.0-1.5 \mathrm{D}$ or more anisohyperopia, $2.0 \mathrm{D}$ or more anisoastigmatism, and $3.0-4.0 \mathrm{D}$ or more anisomyopia. Reciprocal or isoametropic amblyopia may happen within the sight of 5.0 - 6.0 D or a greater amount of nearsightedness, $4.0-5.0 \mathrm{D}$ or a greater amount of hyperopia or 2.0 $3.0 \mathrm{D}$ or a greater amount of astigmatism. Amblyopia brought about by noteworthy astigmatism is alluded to as meridional amblyopia [46] [47] [48] [49] [50].

2) Anisometropia Amblyopia is a seriousness of amblyopia is progressively identified with the isometropia between two eyes, as opposed to the greatness of refractive mistake itself. Levi and associates showed that VA falls quickly with expanding greatness of anisometropia, however that just happens in high isoametropias with exceptionally high refractive levels $(>15 \mathrm{D})$, proposing that systems other than optical haze, particularly unusual binocular communications, are engaged with the danger of amblyopia [51] [52].

Hypermetropic anisometropia is the most probable sort to cause amblyopia, since the retina of the more ametropic eye never gets an unmistakable and characterized picture. The fovea of the great eye is engaged and there will be no upgrade of accommodative exertion to alter the focal point of the more hyperopic eye. In near sighted anisometropia, the more ametropic eye can be utilized for 
close to vision, forestalling indistinguishable degrees of amblyopia from seen with hyperopia [53] [54].

Amblyopia by unadulterated anisometropia is the one with the best anticipation, with the occasionally amazing recuperation of VA with the utilization of satisfactory amendment alone, and even in later treatments. 52 Studies have indicated that the nearness of safeguarded or odd binocular capacity is a significant factor for the recuperation of the framework, despite the fact that a similar examination has demonstrated that notwithstanding great monocular occlusive treatment, different types of adjusted binocular (dichoptic) treatment are perfect for reestablishing typical visual function [55]-[60].

3) Strabismus Amblyopia is a deviation of one eye with loss of eye parallelism. Thus, the eyes don't get equivalent pictures, driving the visual framework to adjust to this change [61].

At the point when the visual framework is totally shaped, the view of non-relating pictures by 2 eyes prompts twofold vision, however when the visual framework is in its basic time of advancement, the cerebrum is as yet equipped for utilizing systems to maintain a strategic distance from diplopia or contention by repressing the actuation of the retinocortical pathways beginning from the fovea of the going amiss eye. This versatile system maintains a strategic distance from diplopia, however it causes a rebuilding of the visual cortical circuits in the visual cortex that thusly causes amblyopia [62].

Steady strabismus causes more serious visual hardship than irregular strabismus [63].

\section{a) Mixed Amblyopia:}

When two factors are responsible for amblyopia development, its called mixed amblyopia. Combination of anisometropic and strabismic amblyopia is common, especially in partially accommodative esotropia, microtropia, and monofixation syndrome [64] [65].

\section{b) Reverse Amblyopia:}

Invert amblyopia is a consequence of penalization of the sound eye with fixing or atropine during amblyopia treatment of the first amblyopic eye. The kind of amblyopia and its seriousness antagonistically influence visual keenness as well as binocularity, differentiate affectability, grinding sharpness, and focal versus unconventional fixation [66].

\section{Diagnosis}

Analysis of amblyopia is really a conclusion of avoidance. Other than Best rectified visual acuity (BCVA), there is no normalized measurement to analyse amblyopia.

In preverbal kids and impaired grown-ups, Visual keenness can be assessed by particular looking methods like Teller sharpness cards, Cardiff keenness test, Fixation inclination tests or picture diagrams like Kay outlines, Lea images. For little youngsters Lea images, Landolt C or HOTV testing are best. By 4 - 5 years 
old, visual sharpness on a Snellen graph, Landolt C, E test, letters, like the STYCAR test utilizing HOTVLXAUC optotypes, or ideally logMAR scale, ETDRS are used [67] [68] [69].

Most visual sharpness tests for amblyopia utilize detached letters encompassed by swarming bars or letters which are introduced in a line of 4 or 5 letters. Visual sharpness tests with single uncrowded letters appear to be heartless toward amblyopia. Swarming (a decrease of visual keenness when optotypes are introduced in a line or encompassed by bars) is by all accounts an element of the creating visual framework, which continues in amblyopia and cerebral visual impairment [70] [71] [72].

Job of OCT in diagnosing amblyopia has become a disputable theme as of late. The estimation of foveal thickness, choroidal and retinal nerve fiber layer thickness has been surveyed in charge gathering and amblyopic patients. In scarcely any examinations it seen that there is a huge distinction found in these values whereas different investigations concede the equivalent. Obviously OCT-An is indicating critical changes in the microvasculature of amblyopic eyes and could be a likely device to analyse and evaluate the treatment progress in amblyopic patients in close future. We need to employ multiple parameters in assessment of amblyopia improvement [73].

\section{Treatment}

Treatment of amblyopia, essential relies upon the sort and cause prompting it. In deprivational amblyopia (because of waterfall, ptosis) adjustment of the reason for visual disability is the essential method of treatment. So also in anisometropic amblyopia refractive rectification with glasses or contact focal points are viewed as first. In strabismic amblyopia it's optimal to treat the strabismus first before continuing with medical procedure as the planning of medical procedure is profoundly controversial 65 . Fixing despite everything remains the best quality level of treatment for the treatment of amblyopia [74].

Over the most recent 20 years, PEDIG (Pediatric Eye Disease Investigator Group), just as MOTAS (Monitored Occlusion Treatment of Amblyopia Study), have led randomized clinical preliminaries to address the fundamental issues of occlusive treatment and to characterize ideal treatment protocols [75] [76] [77] [78].

The PEDIG examines have distributed 17 Amblyopia Treatment Studies (ATS) that are assessing amblyopic treatment for kids 3 to 17 years of age and the significant outcomes to date are:

1) Patching is a viable treatment for amblyopia [79].

2) Optical amendment alone is effective in improving the amblyopia in about $1 / 3$ of patients (anisometropic, strabismic, or mixed).

3) The perfect number of long periods of fixing was assessed. Youngsters 3 to 7 years of age with moderate amblyopia were randomized to 2 hours of fixing for each day contrasted and 6 hours of fixing daily.

4) Atropine for punishment end up being as compelling as impediment. In 
spite of the fact that the impediment bunch had a snappier visual keenness improvement, toward the finish of a half year of treatment there was an equivalent improvement of visual sharpness for the 2 gatherings, and it was kept up in long haul development (as long as 15 years). Notwithstanding the individuals who utilized day by day atropine, patients who utilized atropine once seven days indicated improvement in visual keenness and would do well to compliance.

5) Treatment of amblyopia is best with kids under 7 years old. Kids as long as 13 years old demonstrated huge improvement in vision with fixing, despite the fact that the pace of reaction to treatment might be slower, require a higher portion of fixing, and the degree of recuperation might be less complete [80].

6) There is a high pace of repeat after the finish of amblyopia treatment with comparative rates for impediment and atropine (around 25\%). This rate was multiple times higher in youngsters who didn't have a continuous shape of their treatment for in any event 5 weeks following the goals of amblyopia. Factors likewise connected with more prominent repeat rates included better visual sharpness toward the finish of treatment, more noteworthy number of lines of progress, and past history of recurrence [81].

7) Children fixing with close to work for part of the fixing time had more improvement than kids who fixed with no close to fill in as a feature of the fixing regimen.

Occlusion Side Effects:

Old style unfavourable impacts of impediment treatment are neighbourhood disturbance and sensitivity, debilitated binocularity during treatment, and uncosmetic, and upsetting impact. Clinically noteworthy opposite amblyopia might be initiated by extreme treatment with impediment, however is normally of low frequency as a constant impact $(\leq 1 \%)$, and is typically transient and reversible when treatment is discontinued.

\section{Liquid Crystal Glasses}

Fluid gem glasses have as of late been created as another treatment for amblyopia. Fluid precious stone glasses with the proper revision give an electronic, controlled, discontinuous impediment of the sound eye taking into consideration visual upgrades contribution to the amblyopic individual eye. A fluid gem glass in the sound eye is utilized as an irregular flashing screen exchanged between "on", or impediment, and "off", or light transmission. The gleaming arrangement can be adjusted to the profundity of amblyopia, the length of treatment, and the patient's age.

\section{Opaque (Occluder) Contact Lenses}

Occluder contact focal points can be utilized in the treatment of amblyopia when kids don't conform to fixing. Youngsters can improve treatment consistence utilizing occlusive contact focal points. This treatment is perfect in patients who are fix narrow minded and come up short with customary treatment. These patients ought to have close follow-up so as to forestall foremost fragment inconveniences and amblyopia recurrence [82]. 


\section{Pharmacological Therapy}

As of late Levodopa and Citicoline have been considered as another methodology of treatment as it's accept these medications are answerable for dragging out the basic time frame. Be that as it may, scarcely any investigations repudiate the finding its still far to go.

\section{Binocular therapy/Dichoptic Therapy}

Binocular treatment has been utilized to treat amblyopia in youngsters with no strabismus or little point strabismus with some binocularity. Pictures are introduced dichoptically; high-differentiate pictures are introduced to the amblyopic eye and low-differentiate pictures are introduced to the individual eye. The binocular treatment was adjusted to an $\mathrm{iPad}^{\circledR}$ (Apple, Inc., Cupertino, CA) gadget as a "falling squares" game, which utilizes red-green anaglyphic eyeglasses to permit dichoptic introduction. Albeit early nonrandomized contemplates were promising, results from an ongoing randomized preliminary neglected to exhibit that interactivity endorsed $1 \mathrm{~h}$ for each day was on a par with fixing recommended $2 \mathrm{~h}$ for each day. In spite of the fact that examination is continuous, there is inadequate proof to suggest binocular treatment for the treatment of amblyopia.

\section{Refractive Surgery}

Youngsters who are rebellious to display wear or standard treatment, refractive medical procedure can be valuable for them. In spite of the fact that reasonable focal point extraction can be helpful in hardly any cases however pIOL or PRK may not be exceptionally valuable in numerous events. Presently, there is no huge randomized examination on that yet perhaps PEDIG 19 can through light on the job of refractive surgery as the board of amblyopia.

\section{Role of Physical Activity:}

A few scientists have discovered that patients with amblyopia display oculomotor hindrances incorporating issues with saccadic eye developments, smooth interest, obsession security, hand-eye coordination, hence proposing that focusing on vasomotor circuits during treatment may assist with easing a portion of these deficits [83].

\section{Orthotics:}

Orthotics or eye practice is characterized as a specialist recommended, nonsurgical program of visual exercises to improve visual sharpness and binocularity. These incorporate PC programs, crystals, channels, metronomes, vergence exercises, convenience exercises, anti-suppression exercises, and eye hand coordination works out. These medicines have likewise been advanced for the treatment of amblyopia as an extra to patching [84] [85] [86].

\section{Micro Sensor Therapy:}

Thera Mon micro sensor (Thera Mon ${ }^{\circledR}$-Chip, MC Technology GmbH) is commercially accessible gadget, which permits target documentation of the treatment consistence of patches and glasses. It tests the encompassing temperature in customary stretches. Because of the particular temperatures, it is conceivable to dis- 
tinguish the hour of utilization and, along these lines, the consistence. In this way, Thera Mon micro sensor could be an investigation related methodology for checking the consistence and further prompting conceivable improvement of use time conventions in amblyopia therapy [87].

\section{Reverse Amblyopia:}

Decrease in visual sharpness in sound eye while rewarding the amblyopic eye. It could be a result of unnecessary treatment by fixing or penalisation. It's generally transient and reversible. In ATS, visual sharpness in the sound eye at half year assessment was diminished by 1 line in $7 \%$ of patients in the fixing gathering and $15 \%$ in the atropine gathering. A two or more lines decline was seen in $1 \%$ of the fixing gathering and $9 \%$ of the atropine gathering. Just 1 patient (from atropine gathering) was effectively rewarded for an assumed converse amblyopia, with an arrival of visual sharpness to its pattern level seen more on persistent accepting joined treatment. Visit follow up of such cases are recommended [88].

\section{Recurrence of Amblyopia:}

The elements influencing amblyopia repeat are not satisfactory. It has been proposed that helpless introductory visual sharpness, strabismic amblyopia and low age toward the finish of treatment are hazard factors for amblyopia repeat after treatment discontinuance. Most noteworthy rate of repeat has been seen inside $1 \mathrm{yr}$ following suspension of treatment. Prior to treatment suspension, treatment ought to be weaned so as to maintain a strategic distance from repeat. After treatment suspension, kids ought to be followed for at any rate one year, with specific accentuation on the initial a half year. Strabismic patients are particularly in danger for recurrence [89] [90].

\section{Conclusion}

There are no changes that occurred since a decade ago in understanding one of the regular ophthalmic issues. A number of studies are currently going on. These have changed our point of view in the conclusion and the executives of amblyopia at a noteworthy level. We know well now as the basic time frame is not as basic as once accepted and treatment of amblyopia can in any case be possible even at a later age.

\section{Conflicts of Interest}

The authors declare no conflicts of interest regarding the publication of this paper.

\section{References}

[1] Von Noorden, G.K. (1996) Binocular Vision and Ocular Motility. Mosby, St. Lous.

[2] Zhao, P.F., Zhou, Y.H., Wang, N.L. and Zhang, J. (2010) Study of the Wave Front Aberrations in Children with Amblyopia. Chinese Medical Journal, 123, 1431-1435.

[3] De Zárate, B.R. and Tejedor, J. (2007) Current Concepts in the Management of Amblyopia. Clinical Ophthalmology, 1, 403-414 
[4] Quah, B.L., Tay, M.T., Chew, S.J. and Lee, L.K. (1991) A Study of Amblyopia in 18-19 Year Old Males. Singapore Medical Journal, 32, 126-129.

[5] Epelbaum, M., Milleret, C., Buisseret, P. and Dufier, J.L. (1993) The Sensitive Period for Strabismic Amblyopia in Humans. Ophthalmology, 100, 323-327.

https://doi.org/10.1016/S0161-6420(13)32170-8

[6] Flynn, J.T., Schiffman, J., Feuer, W. and Corona, A. (1998) The Therapy of Amblyopia: An Analysis of the Results of Amblyopia Therapy Utilizing the Pooled Data of Published Studies. Transactions of the American Ophthalmological Society, 96, 431-453.

[7] Simons, K. and Preslan, M. (1999) Natural History of Amblyopia Untreated Owing to Lack of Compliance. British Journal of Ophthalmology, 83, 582-587.

https://doi.org/10.1136/bjo.83.5.582

[8] Assaf, A.A. (1982) The Sensitive Period: Transfer of Fixation after Occlusion for Strabismic Amblyopia. British Journal of Ophthalmology, 66, 64-70. https://doi.org/10.1136/bjo.66.1.64

[9] Woodruff, G., Hiscox, F., Thompson, J.R. and Smith, L.K. (1994) Factors Affecting the Outcome of Children Treated for Amblyopia. Eye, 8, 627-631.

https://doi.org/10.1038/eye.1994.157

[10] Simmers, A.J. and Gray, L.S. (1999) Improvement of Visual Function in an Adult Amblyope. Optometry and Vision Science, 76, 82-87. https://doi.org/10.1097/00006324-199902000-00014

[11] Pediatric Eye Disease Investigator Group (2004) A Prospective, Pilot Study of Treatment of Amblyopia in Children 10 to $<18$ Years Old. American Journal of Ophthalmology, 137, 581-583. https://doi.org/10.1016/j.ajo.2003.08.043

[12] Mohan, K., Saroha, V. and Sharma, A. (2004) Successful Occlusion Therapy for Amblyopia in 11- to 15-Year-Old Children. Journal of Pediatric Ophthalmology and Strabismus, 41, 89-95. https://doi.org/10.3928/0191-3913-20040301-08

[13] Brown, M.H. and Edelman, P.M. (1976) Conventional Occlusion in the Older Amblyope. American Orthoptic Journal, 26, 34-36. https://doi.org/10.1080/0065955X.1976.11982398

[14] Sen, D.K. (1984) Results of Treatment in Amblyopia Associated with Unilateral High Myopia without Strabismus. British Journal of Ophthalmology, 68, 681-685. https://doi.org/10.1136/bjo.68.9.681

[15] Oliver, M., Neumann, E., Chaimovitch, Y., Gotesman, N. and Shimshoni, M. (1986) Compliance and Results of Treatment for Amblyopia in Children More than 8 Years Old. American Journal of Ophthalmology, 102, 340-345. https://doi.org/10.1016/0002-9394(86)90008-5

[16] Noda, S., Hayasaka, S. and Setogawa, T. (1993) Occlusion Therapy of Japanese Children with Anisometropic Amblyopia without Strabismus. Annals of Ophthalmology, 25, 145-147.

[17] Tsubota, K. and Yamada, M. (1994) Treatment of Amblyopia by Extended-Wear Occlusion Soft Contact Lenses. Ophthalmologica, 208, 214-215.

https://doi.org/10.1159/000310491

[18] Mintz-Hittner, H.A. and Fernandez, K.M. (2000) Successful Amblyopia Therapy initiated after Age 7 Years: Compliance Cures. Archives of Ophthalmology, 118, 1535-1541. https://doi.org/10.1001/archopht.118.11.1535

[19] Kupfer, C. (1957) Treatment of Amblyopia Exanopsia in Adults. A Preliminary Report of Seven Cases. American Journal of Ophthalmology, 43, 918-922. 
https://doi.org/10.1016/0002-9394(57)91795-6

[20] Wick, B., Wingard, M., Cotter, S. and Scheiman, M. (1992) Anisometropic Amblyopia: Is the Patient Ever Too Old to Treat? Optometry and Vision Science, 69, 866-878. https://doi.org/10.1097/00006324-199211000-00006

[21] Park, K.H., Hwang, J.M. and Ahn, J.K. (2004) Efficacy of Amblyopia Therapy Initiated after 9 Years of Age. Eye, 18, 571-574. https://doi.org/10.1038/sj.eye.6700671

[22] Magoon, E.H. and Garuda, S. (2000) Visual Acuity Plasticity in Amblyopes between Age 10 and 14. In: Scott, A., Ed., Proceedings of the Jampolsky Festschrift Olsky Festschrift, San Francisco.

[23] Zagui, R.M.B. (2018) Amblyopia: Types, Diagnosis, Treatment, and New Perspectives. American Academy of Ophthalmology, 102, 1492-1496.

[24] Davis, A.R., Sloper, J.J., Neveu, M.M., Hogg, C.R., Morgan, M.J. and Holder, G.E. (2006) Differential Changes of Magnocellular and Parvocellular Visual Function in Early- and Late-Onset Strabismic Amblyopia. Investigative Ophthalmology \& Visual Science, 47, 4836-4841. https://doi.org/10.1167/iovs.06-0382

[25] Sloper, J. (2016) The Other Side of Amblyopia. Journal of the American Association for Pediatric Ophthalmology and Strabismus, 20, E1-1. E13.

https://doi.org/10.1016/j. Journal of the American Association for Pediatric Ophthalmology and Strabismus.2015.09.013

[26] Herbison, N., Cobb, S., Gregson, R., Ash, I., Eastgate, R., Purdy, J., et al. (2013) Interactive Binocular Treatment (I-BiT) for Amblyopia: Results of a Pilot Study of 3D Shutter Glasses System. Eye, 27, 1077-1083. https://doi.org/10.1038/eye.2013.113

[27] Li, J., Thompson, B., Deng, D., Chan, L.Y., Yu, M., Hess, R.F., et al. (2013) Dichoptic Training Enables the Adult Amblyopic Brain to Learn. Current Biology, 23, 308-309. https://doi.org/10.1016/j.cub.2013.01.059

[28] Spiegel, D.P., Li, J., Hess, R.F., Byblow, W.D., Deng, D., Yu, M., et al. (2013) Transcranial Direct Current Stimulation Enhances Recovery of Stereopsis in Adults with Amblyopia. Neurotherapeutics, 10, 831-839. https://doi.org/10.1007/s13311-013-0200-y

[29] Leguire, L.E., Rogers, G.L., Walson, P.D., Bremer, D.L. and Mcgregor, M.L. (1998) Occlusion and Levodopa-Carbidopa Treatment for Childhood Amblyopia. Journal of the American Association for Pediatric Ophthalmology and Strabismus, 2, 257-264. https://doi.org/10.1016/S1091-8531(98)90080-5

[30] Mohan, K., Dhankar, V. and Sharma, A. (2001) Visual Acuities after Levodopa Administration in Amblyopia. Journal of Pediatric Ophthalmology and Strabismus, 38, 62-67.

[31] Repka, M.X., Kraker, R.T., Beck, R.W., Atkinson, C.S., Bacal, D.A., Bremer, D.L., et al. (2010) Pilot Study of Levodopa Dose as Treatment for Residual Amblyopia in Children Aged 8 Years to Younger than 18 Years. Archives of Ophthalmology, 128, 1215-1217. https://doi.org/10.1001/archophthalmol.2010.178

[32] Dadeya, S., Vats, P. and Malik, K.P. (2009) Levodopa/Carbidopa in the Treatment of Amblyopia. Journal of the American Association for Pediatric Ophthalmology and Strabismus, 46, 87-90.

[33] Morishita, H., Miwa, J.M., Heintz, N. and Hensch, T.K. (2010) Lynx1, a Cholinergic Brake, Limits Plasticity in Adult Visual Cortex. Science, 330, 1238-1240. https://doi.org/10.1126/science.1195320

[34] Zhao, J., Lam, D.S., Chen, L.J., Wang, Y., Zheng, C., Lin, Q., et al. (2010) Randomized Controlled Trial of Patching vs Acupuncture for Anisometropic Amblyopia 
in Children Aged 7 to 12 Years. Archives of Ophthalmology, 128, 1510-1517. https://doi.org/10.1001/archophthalmol.2010.306

[35] Lam, D.S., Zhao, J., Chen, L.J., Wang, Y., Zheng, C., Lin, Q., et al. (2011) Adjunctive Effect of Acupuncture to Refractive Correction on Anisometropic Amblyopia: one-Year Results of a Randomized Crossover Trial. Ophthalmology, 118, 1501-1511. https://doi.org/10.1016/j.ophtha.2011.01.017

[36] Althomali, T.A. (2013) Posterior Chamber Toricphakic IOL Implantation for the Management of Pediatric Anisometropicamblyopia. Journal of Refractive Surgery, 29, 396-400. https://doi.org/10.3928/1081597X-20130410-01

[37] Paysse, E.A., Coats, D.K., Hussein, M.A., Hamill, M.B. and Koch, D.D. (2006) Long-Term Outcomes of Photorefractive Keratectomy for Anisometropic Amblyopia in Children. Ophthalmology, 113, 169-176.

https://doi.org/10.1016/j.ophtha.2005.06.010

[38] Joslin, C.E., Mcmahon, T.T. and Kaufman, L.M. (2002) The Effectiveness of Occluder Contact Lenses in Improving Occlusion Compliance in Patients That Have Failed Traditional Occlusion Therapy. Optometry and Vision Science, 79, 376-380. https://doi.org/10.1097/00006324-200206000-00011

[39] Pradeep, A., Proudlock, F.A., Awan, M., Bush, G., Collier, J., Gottlob, I., et al. (2014) An Educational Intervention to Improve Adherence to High-Dosage Patching Regimen for Amblyopia: A Randomised Controlled Trial. British Journal of Ophthalmology, 98, 865-870. https://doi.org/10.1136/bjophthalmol-2013-304187

[40] Medghalchi, A.R. and Dalili, S. (2011) A Randomized Trial of Atropine vs Patching for Treatment of Moderate Amblyopia. Iranian Red Crescent Medical Journal, 13, 578-581

[41] Holmes, J.M. and Pediatric Eye Disease Investigator Group (2005) A Randomized Pilot Study of Near Activities versus Non-Near Activities during Patching Therapy for Amblyopia. Journal of the American Association for Pediatric Ophthalmology and Strabismus, 9, 129-136.

https://doi.org/10.1016/j. Journal of the American Association for Pediatric Ophthalmology and Strabismus.2004.12.014

[42] Gopal, S.K., Kelkar, J., Kelkar, A. and Pandit, A. (2019) A Simplified Updates on the Pathophysiology and Recent Developments in the Treatment of Amblyopia: A Review. Indian Journal of Ophthalmology, 67, 1392-1399. https://doi.org/10.4103/ijo.IJO 1119

[43] Birch, E.E. and Stager, D.R. (1996) The Critical Period for Surgical Treatment of Dense Congenital Unilateral Cataract. Investigative Ophthalmology \& Visual Science, 37, 1532-1538. https://doi.org/10.1016/S0002-9394(14)70512-4

[44] Hamm, L., Chen, Z., Li, J., Black, J., Dai, S., Yuan, J., et al. (2017) Interocular Suppression in Children with Deprivation Amblyopia. Vision Research, 133, 112-120. https://doi.org/10.1016/j.visres.2017.01.004

[45] Hamm, L.M., Chen, Z., Li, J., Dai, S., Black, J., Yuan, J., et al. (2018) Contrast-Balanced Binocular Treatment in Children with Deprivation Amblyopia. Clinical and Experimental Optometry, 101, 541-552. https://doi.org/10.1111/cxo.12630

[46] Dk, P. (1996) Anisometropia. In: Brookman, K.E., Ed., Refratometria ocular e a arte da prescrição médica, Butterman-Heinemann, Boston, 99-121.

[47] Levi, D.M., Mckee, S.P. and Movshon, J.A. (2011) Visual Deficits in Anisometropia. Vision Res, 51, 48-57. https://doi.org/10.1016/j.visres.2010.09.029

[48] Helveston, E.M. (1966) Relationship between Degree of Anisometropia and Depth 
of Amblyopia. American Journal of Ophthalmology, 62, 757-759. https://doi.org/10.1016/0002-9394(66)92207-0

[49] Hess, R.F., Mansouri, B. and Thompson, B. (2011) Restoration of Binocular Vision in Amblyopia. Strabismus, 19, 110-118. https://doi.org/10.3109/09273972.2011.600418

[50] Li, S.L., Reynaud, A., Hess, R.F., Wang, Y.Z., Jost, R.M., Morale, S.E., et al. (2015) Dichoptic Movie Viewing Treats Childhood Amblyopia. Journal of the American Association for Pediatric Ophthalmology and Strabismus, 19, 401-405. https://doi.org/10.1016/j. Journal of the American Association for Pediatric Ophthalmology and Strabismus.2015.08.003

[51] Birch, E.E., Li, S.L., Jost, R.M., Morale, S.E., De La Cruz, A., Stager, D., et al. (2015) Binocular Ipad Treatment for Amblyopia in Preschool Children. Journal of the American Association for Pediatric Ophthalmology and Strabismus, 19, 6-11. https://doi.org/10.1016/j. Journal of the American Association for Pediatric Ophthalmology and Strabismus.2014.09.009

[52] Cotter, S.A., Edwards, A.R., Wallace, D.K., Beck, R.W., Arnold, R.W., Astle, W.F., et al. and Pediatric Eye Disease Investigator Group (2006) Treatment of Anisometropic Amblyopia in Children with Refractive Correction. Ophthalmology, 113, 895-903. https://doi.org/10.1016/j.ophtha.2006.01.068

[53] Copps, L.A. (1944) Vision in Anisometropia. American Journal of Ophthalmology, 27, 641-644. https://doi.org/10.1016/S0002-9394(44)91523-0

[54] Toor, S., Horwood, A.M. and Riddell, P. (2018) Asymmetrical Accommodation in Hyperopic Anisometropic Amblyopia. British Journal of Ophthalmology, 102, 772-778. https://doi.org/10.1136/bjophthalmol-2017-310282

[55] Zagui, R.B.M. (2019) Amblyopia: Types, Diagnosis, Treatment, and New Perspectives. American Academy of Ophthalmology, 25, 2-4.

[56] Korah, S., Philip, S., Jasper, S., Antonio-Santos, A. and Braganza, A. (2014) Strabismus Surgery before verus after Completion of Amblyopia Therapy in Children. Cochrane Database of Systematic Reviews, 10, CD009272. https://doi.org/10.1002/14651858.CD009272.pub2

[57] 2014-2015 BCSC, Pediatric Section 6: Ophthalmology and Strabismus?

[58] (2015) In Dynamed. EBSCO Information Services.

[59] Weakley Jr., D.R. (2001) The Association between Nonstrabismic Anisometropia, Amblyopia, and Subnormal Binocularity. Ophthalmology, 108, 163-171. https://doi.org/10.1016/S0161-6420(00)00425-5

[60] Braverman, R.S. (2015) Types of Amblyopia. American Academy of Ophthalmology, 10, 3-4.

[61] Rydberg, A., Ericson, B., Lennerstrand, G., Jacobson, L. and Lindstedt, E. (1999) Assessment of Visual Acuity in Children Aged 11/2-6 Years, with Normal and Subnormal Vision. Strabismus, 7, 1-24. https://doi.org/10.1076/stra.7.1.1.656

[62] Atkinson, J. and Braddick, O. (1983) Assessment of Visual Acuity in Infancy and Early Childhood. Acta Ophthalmologica, 157, 18-26. https://doi.org/10.1111/j.1755-3768.1983.tb03927.x

[63] Wong, E.S. (2020) Association of Optical Coherence Tomography Angiography Metrics with Detection of Impaired Macular Microvasculature and Decreased Vision in Amblyopic Eyes the Hong Kong Children Eye Study. JAMA Ophthalmolo$g y, 138,858-865$.

[64] Lim, T.H. and Tan, C.S. (2020) Optical Coherence Tomography Angiography as an 
Important Diagnostic Tool for Amblyopia. JAMA Ophthalmology, 138, 865-866. https://doi.org/10.1001/jamaophthalmol.2020.2219

[65] Lam, G.C., Repka, M.X. and Guyton, D.L. (1993) Timing of Amblyopia Therapy Relative to Strabismus Surgery. Ophthalmology, 100, 1751-1756. https://doi.org/10.1016/S0161-6420(13)31403-1

[66] PEDIG. Amblyopia Treatment Study Index. https://public.jaeb.org/pedig/pubs

[67] PEDIG. Pediatric Eye Disease Investigator Group. https://public.jaeb.org/pedig/pubs

[68] Stewart, C.E., Fielder, A.R., Stephens, D.A. and Moseley, M.J. (2002) Design of the Monitored Occlusion Treatment of Amblyopia Study (MOTAS). British Journal of Ophthalmology, 86, 915-919. https://doi.org/10.1136/bjo.86.8.915

[69] Writing Committee for the Pediatric Eye Disease Investigator Group, Cotter, S.A., Foster, N.C., Holmes, J.M., Melia, B.M., Wallace, D.K., Repka, M.X., et al. (2012). Optical Treatment of Strabismic and Combined Strabismic-Anisometropic Amblyopia. Ophthalmology, 119, 150-158. https://doi.org/10.1016/j.ophtha.2011.06.043

[70] Pediatric Eye Disease Investigator Group, Wallace, D.K., Edwards, A.R., Cotter, S.A., Beck, R.W., Arnold, R.W., Astle, W.F., et al. (2006) A Randomized Trial to Evaluate 2 Hours of Daily Patching for Strabismic and Anisometropic Amblyopia in Children. Ophthalmology, 113, 904-912.

https://doi.org/10.1016/j.ophtha.2006.01.069

[71] Repka, M.X., Beck, R.W., Holmes, J.M., Birch, E.E., Chandler, D.L., Cotter, S.A., et al. and Pediatric Eye Disease Investigator Group (2003) A Randomized Trial of Patching Regimens for Treatment of Moderate Amblyopia in Children. Archives of Ophthalmology, 121, 603-611. https://doi.org/10.1001/archopht.121.5.603

[72] Repka, M.X., Kraker, R.T., Holmes, J.M., Summers, A.I., Glaser, S.R., Barnhardt, C.N., et al. and Pediatric Eye Disease Investigator Group (2014) Atropine vs Patching for Treatment of Moderate Amblyopia: Follow-Up at 15 Years of Age of a Randomized Clinical Trial. JAMA Ophthalmology, 132, 799-805.

https://doi.org/10.1001/jamaophthalmol.2014.392

[73] Holmes, J.M., Lazar, E.L., Melia, B.M., Astle, W.F., Dagi, L.R., Donahue, S.P., et al. and Pediatric Eye Disease Investigator Group (2011) Effect of Age on Response to Amblyopia Treatment in Children. Archives of Ophthalmology, 129, 1451-1457. https://doi.org/10.1001/archophthalmol.2011.179

[74] Holmes, J.M., Melia, M., Bradfield, Y.S., Cruz, O.A., Forbes, B. and Pediatric Eye Disease Investigator Group (2007) Factors Associated with Recurrence of Amblyopia on Cessation of Patching. Ophthalmology, 114, 1427-1432.

https://doi.org/10.1016/j.ophtha.2006.11.023

[75] Birch, E.E., Fawcett, S.L., Morale, S.E., Weakley Jr., D.R. and Wheaton, D.H. (2005) Risk Factors for Accommodative Esotropia among Hypermetropic Children. Investigative Ophthalmology \& Visual Science, 46, 526-529. https://doi.org/10.1167/iovs.04-0618

[76] Pediatric Eye Disease Investigator Group (2008) A Randomized Trial of Near Versus Distance Activities While Patching for Amblyopia in Children Aged 3 to Less Than 7 Years. Ophthalmology, 115, 2071-2078. https://doi.org/10.1016/j.ophtha.2008.06.031

[77] The Pediatric Eye Disease Investigator Group (2002) A Randomized Trial of Atropine vs Patching for Treatment of Moderate Amblyopia in Children. Archives of Ophthalmology, 120, 268-278. https://doi.org/10.1001/archopht.120.3.268 
[78] Gottlob, I., Wizov, S.S. and Reinecke, R.D. (1995) Visual Acuities and Scotomas after 3 Weeks' Levodopa Administration in Adult Amblyopia. Graefe's Archive for Clinical and Experimental Ophthalmology, 233, 407-413. https://doi.org/10.1007/BF00180943

[79] Leguire, L.E., Komaromy, K.L., Nairus, T.M. and Rogers, G.L. (2002) Long-Term Follow-Up of L-Dopa Treatment in Children with Amblyopia. Journal of Pediatric Ophthalmology and Strabismus, 39, 326-330. https://doi.org/10.3928/0191-3913-20021101-05

[80] Bhartiya, P., Sharma, P., Biswas, N.R., Tandon, R. and Khokhar, S.K. (2002) Levodopa-Carbidopa with Occlusion in Older Children with Amblyopia. Journal of American Association for Pediatric Ophthalmology and Strabismus, 6, 368-372. https://doi.org/10.1067/mpa.2002.129043

[81] Kraus, C.L. and Culican, S.M. (2018) New Advances in Amblyopia Therapy II: Refractive Therapies. British Journal of Ophthalmology, 102, 1611-1614.

https://doi.org/10.1136/bjophthalmol-2018-312173

[82] Perdziak, M., Witkowska, D.K., Gryncewicz, W. and Ober, J.K. (2016) Not only Amblyopic but Also Dominant Eye in Subjects with Strabismus Show increased Saccadic Latency. Journal of Vision, 16, 12. https://doi.org/10.1167/16.10.12

[83] Raashid, R.A., Liu, I.Z., Blakeman, A., Goltz, H.C. and Wong, A.M. (2016) The Initiation of Smooth Pursuit Is Delayed in Anisometropic Amblyopia. Investigative Ophthalmology \& Visual Science, 57, 1757-1764. https://doi.org/10.1167/iovs.16-19126

[84] Chung, S.T., Kumar, G., Li, R.W. and Levi, D.M. (2015) Characteristics of Fixational Eye Movements in Amblyopia: Limitations on Fixation Stability and Acuity? Vision Research, 114, 87-99. https://doi.org/10.1016/j.visres.2015.01.016

[85] Niechwiej-Szwedo, E., Goltz, H.C., Chandrakumar, M. and Wong, A.M. (2014) Effects of Strabismic Amblyopia and Strabismus without Amblyopia on Visuomotor Behavior: III. Temporal Eye-Hand Coordination during Reaching. Investigative Ophthalmology \& Visual Science, 55, 7831-7838. https://doi.org/10.1167/iovs.14-15507

[86] Stryker, M.P. and Loewel, S. (2018) Amblyopia: New Molecular/Pharmacological and Environmental Approaches. Visual Neuroscience, 35, E018. https://doi.org/10.1017/S0952523817000256

[87] Januschowski, K., Rickmann, A., Emmerich, C., Abaza, A., Bechtold, T.E., Schott, T.C., et al. (2017) Der Einsatz eines Mikrosensors in der Amblyopietherapie. Klinische Monatsblätter für Augenheilkunde, 236, 1170-1173. https://doi.org/10.1055/s-0043-118221

[88] Morrison, D.G., Palmer, N.J., Sinatra, R.B. and Donahue, S. (2005) Severe Amblyopia of the Sound Eye Resulting from Atropine Therapy Combined with Optical Penalization. Journal of Pediatric Ophthalmology and Strabismus, 42, 52-53. https://doi.org/10.3928/01913913-20050101-07

[89] Nilsson, J., Baumann, M. and Sjöstrand, J. (2007) Strabismus Might Be a Risk Factor for Amblyopia Recurrence. Journal of the American Association for Pediatric Ophthalmology and Strabismus, 11, 240-242.

https://doi.org/10.1016/j. Journal of the American Association for Pediatric Ophthalmology and Strabismus.2007.01.117

[90] Bhola, R., Keech, R.V., Kutschke, P., Pfeifer, W. and Scott, W.E. (2006) Recurrence of Amblyopia after Occlusion Therapy. Ophthalmology, 113, 2097-2100. https://doi.org/10.1016/j.ophtha.2006.04.034 